https://doi.org/10.15407/ujpe63.4.370

S.G. ORLOVSKAYA, V.V. KALINCHAK, O.N. ZUJ, M.V. LISEANSKAIA

I.I. Mechnikov Odessa National University

(2, Dvoryanskaya Str., Odessa 65082, Ukraine; e-mail: svetor25@gmail.com)

\title{
STUDY OF IGNITION AND COMBUSTION OF TWO-FRACTION COAL-AIR SUSPENSION
}

\begin{abstract}
A two-fraction dust-air mixture is the simplest example of polydisperse suspensions. We aim to study the characteristics of ignition and combustion of a two-fraction suspension of carbon particles in air at different temperatures. The main characteristics of the dispersed fuel combustion are the ignition delay, burning temperature and time, and critical parameters (temperature, diameters of particles, and mass concentrations) corresponding to the fuel ignition and extinction. The high-temperature heat and mass transfer and chemical kinetics are modeled for a two-fraction particles-gas suspension (diameter of fine particles $60 \mu \mathrm{m}$ and for that with coarse particles $120 \mu \mathrm{m}$ ) with equal mass fractions. The gas temperature is varied in the interval between $1100 \mathrm{~K}$ and $1500 \mathrm{~K}$.

Ke ywords: combustion, carbon, gas suspension, ignition.
\end{abstract}

\section{Introduction}

The need to reduce emissions of carbon dioxide and particulate matter into the atmosphere requires increasing the effectiveness of coal dust combustion. The carbon fuel burnt in power stations contains particles of different sizes. A simple case of such fuel is two-fraction dust-air suspensions. The aim of the work is to study the characteristics of ignition, burning, and extinction of two-fraction carbon particles in an air suspension at different temperatures.

The main characteristics of the disperse fuel combustion are: the ignition delay, the burning temperature and time, the critical temperatures, the diameters of particles, and mass concentrations, which determine their ignition and extinction $[1,2]$.

\section{Physical and Mathematical}

Modeling of High-Temperature Processes

in Two-Fraction Coal-Air Suspension of Carbon Particles

The research includes the physico-mathematical modeling of the high-temperature heat and mass transfer and the kinetics of chemical transformations of carbon particles in an oxidizing gaseous medium. As the first approximation, a two-fraction carbon particlesgas suspension containing equal mass concentrations

(c) S.G. ORLOVSKAYA, V.V. KALINCHAK, O.N. ZUJ, M.V. LISEANSKAIA, 2018 of fine particles (diameter $60 \mu \mathrm{m}$ ) and coarse particles $(120 \mu \mathrm{m})$ is considered. The gas temperature ranges from $1100 \mathrm{~K}$ to $1500 \mathrm{~K}$.

The physico-mathematical model of high-temperature heat and mass transfer of the carbon particlesgas suspension includes the differential equations of thermal and mass balances for the particles of each fraction and the corresponding equations for oxygen-containing gas $[3,4]$. We will study the hightemperature heat and mass transfer and the kinetics of the chemical transformation of a two-fraction gas suspension of carbon particles with particle diameters that differ by several times with equal mass concentrations.

Let us consider the non-stationary heat and mass transfer of a polydisperse suspension of carbon particles in air. On the surface of particles, two parallel chemical reactions occur:

$\mathrm{C}+\mathrm{O}_{2}=\mathrm{CO}_{2}(\mathrm{I}), 2 \mathrm{C}+\mathrm{O}_{2}=2 \mathrm{CO}(\mathrm{II})$.

The heat balance equation for the particle of the $i$-th fraction is written in the following form, taking into account its heat exchange with the gas and the walls of the reaction vessel:

$\frac{c \rho d_{i}}{6} \frac{\partial T_{i}}{\partial t}=q_{c h i}-q_{\alpha i}-q_{w i}, T_{i}(t=0)=T_{i b}$,

where $c$ - the particle specific heat, $\mathrm{J} / \mathrm{kg} \cdot \mathrm{K} ; \rho_{i}$ - the particle density, $\mathrm{kg} / \mathrm{m}^{3} ; d_{i}$ - the particle diameter of the $i$-th fraction, $\mathrm{m} ; T_{i}, T_{i b}$ - are the current and initial temperatures of a particle, $\mathrm{K} ; t-$ time, s; $q_{c h i}-$

ISSN 2071-0194. Ukr. J. Phys. 2018. Vol. 63, No. 4 
the total density of chemical heat release at the surface and in the pores of a particle, $\mathrm{W} / \mathrm{m}^{2} ; q_{\alpha i}-$ the heat flux density at the particle surface, $\mathrm{W} / \mathrm{m}^{2} ; q_{w i}-$ the density of the radiation heat flux from the particle to the reaction vessel walls, $\mathrm{W} / \mathrm{m}^{2}$.

The total density of chemical heat release on the outer and inner surfaces of the particle, according to $[5,6]$, is determined from the expression:

$q_{c h i}=\left(k_{1 i} q_{1}+k_{2 i} q_{2}\right) P_{v i} \rho_{g} n_{\mathrm{O}_{2}, s i}$,

where $k_{1 i}, k_{2 i}$ - rate constants of chemical reactions (I) and (II), m/s; $q_{1}, q_{2}$ - thermal effects of chemical reactions (I) and (II) calculated per unit oxygen mass, $\mathrm{J} / \mathrm{kg} \cdot \mathrm{O}_{2} ; \rho_{g}-$ gas density, $\mathrm{kg} / \mathrm{m}^{3} ; n_{\mathrm{O}_{2}, s i}-$ relative mass concentration of oxygen on the surface of a carbonaceous particle.

We write the expression for the concentration of oxygen on the surface of a particle:

$$
n_{\mathrm{O}_{2}, s i}=\frac{\beta_{i}}{\beta_{i}+\left(k_{1 i}+k_{2 i}+P_{s f i}\right) P_{v i}} n_{\mathrm{O}_{2}, g} .
$$

The heat exchange of each particle with a gas is determined by the density of the heat flux on the surface of a particle $q_{\alpha i}$, including the heat transfer by conduction, convection, and Stefan flow [7]:

$q_{\alpha i}=\alpha_{i}\left[\left(T_{i}-T_{g}\right)+\frac{U_{s f i}}{2}\left(T_{i}+T_{g}\right)\right]$,

$\alpha_{i}=\frac{\mathrm{Nu} \lambda_{g}}{d_{i}}$,

where $\alpha_{i}$ is the heat exchange coefficient of the particle, $\mathrm{W} / \mathrm{m}^{2} \cdot \mathrm{K} ; \lambda_{g}$ is the gas thermal conductivity, $\mathrm{W} / \mathrm{m} \cdot \mathrm{K}, T_{g}$ is the gas temperature, $\mathrm{K}$.

We write down the expression for the radiation heat flux per unit area of a particle to the walls of the reaction vessel by using the known formulas of StefanBoltzmann and Kirchhoff:

$q_{w i}=\varepsilon \sigma\left(T_{i}^{4}-T_{w}^{4}\right)$,

where $\varepsilon$ is the emissivity of carbon; $\mathrm{T}_{\mathrm{w}}$ - temperature of the reaction vessel walls, $K ; \sigma=5.67 \mathrm{~W} / \mathrm{m}^{2} \cdot \mathrm{K}^{4}$ is the Stefan-Boltzmann constant.

During the coal suspension burning, the particle diameter and density decrease with time due to the chemical reactions on the outer and inner surfaces of particles (inside the pores). The differential equations of mass balance for the diameter and density of a carbon particle of the $i$-th fraction can be written as

$-\frac{1}{2} \rho_{i} \frac{\partial\left(d_{i}\right)}{\partial t}=\frac{M_{\mathrm{C}}}{M_{\mathrm{O}_{2}}}\left(k_{1 i}+2 k_{2 i}\right) n_{\mathrm{O}_{2}, s i} \rho_{g}$,

$d_{i}(t=0)=d_{b i}$,

$-\frac{1}{6} d_{i} \frac{\partial\left(\rho_{i}\right)}{\partial t}=\frac{M_{\mathrm{C}}}{M_{\mathrm{O}_{2}}}\left(k_{1 i}+2 k_{2 i}\right) n_{\mathrm{O}_{2}, s i} \frac{k_{v i}}{k_{1 i}+k_{2 i}} \rho_{g}$,

$\rho_{i}(t=0)=\rho_{b i}$,

where $d_{b i}$ - the particle initial diameter, $m ; \rho_{b i}-$ initial particle density, $\mathrm{kg} / \mathrm{m}^{3}$.

The important parameter of the gas suspension is its mass concentration $C_{m}$, which depends on the particle diameter and the numerical concentration $C_{N}$ :

$C_{m}=\sum_{i=1}^{n} C_{m i}, \quad C_{m i}=\frac{1}{6} \pi d_{i}^{3} \rho_{i} C_{N i}, \quad C_{N i}=\frac{N_{i}}{V_{g}}$,

where $C_{m i}$ is the mass concentration, $\mathrm{kg} / \mathrm{m}^{3}$, and $C_{N i}$ is the numerical concentration, $\mathrm{m}^{-3}$ of the $i$-th fraction of the solid phase of the suspension; $N_{i}$ is the number of particles in the $i$-th fraction.

Thus, as the combustion proceeds, the fuel mass concentration reduces, as the particle diameter and the density decrease, and the numerical concentration is unchanged till the moment of complete burn-out.

During the suspension burning, the gas temperature and the oxidizer content change with time:

$c_{g} \rho_{g} \frac{\partial T_{g}}{\partial t}=\sum_{i=1}^{n} \alpha_{i} S_{i} C_{N i}\left[\left(T_{i}-T_{g}\right)+\frac{U_{s f i}}{2 \beta_{i}}\left(T_{i}+T_{g}\right)\right]-$

$-\alpha_{g} F_{g}\left(T_{g}-T_{g \infty}\right), T_{g}(t=0)=T_{g \infty}$,

$\alpha_{g}=\frac{\mathrm{Nu}_{g} \lambda_{g}}{d_{g}}, F_{g}=\frac{S_{g}}{V_{g}}$,

$-\frac{\partial n_{\mathrm{O}_{2 g}}}{\partial t}=\sum_{i=1}^{n} C_{N i} S_{i} n_{\mathrm{O}_{2}, s i}\left(k_{1 i}+k_{2 i}+k_{v i}\right)-$

$-F_{g} \beta_{g}\left(n_{\mathrm{O}_{2}, \infty}-n_{\mathrm{O}_{2 g}}\right), \quad n_{\mathrm{O}_{2 g}}(t=0)=n_{\mathrm{O}_{2}, \infty}$,

$\beta_{g}=\frac{S h_{g} D_{g}}{d_{g}}, D_{g}=\frac{\lambda_{g}}{c_{g} \rho_{g}}$,

where $S_{i}$ is the particle surface area (the $i$-th fraction), $\mathrm{m}^{2} ; c_{g}$ - specific heat of a gas, $\mathrm{J} / \mathrm{kg} \cdot \mathrm{K} ; T_{g \infty}-$ surrounding gas temperature, $\mathrm{K} ; \alpha_{g}$ - heat transfer coefficient of the carbon particles-gas suspension with the surrounding medium, $\mathrm{W} / \mathrm{m}^{2} \cdot \mathrm{K} ; N u_{g}$ - Nusselt number corresponding to the heat transfer of the particles-gas suspension with the surrounding medium; 
$F_{g}$ - specific surface area of the particles-gas suspension, $\mathrm{m}^{-1} ; S_{g}$ - the outer surface area of the suspension, $\mathrm{m}^{2}, \beta_{g}$ - mass-transfer coefficient of the suspension with the environment, $\mathrm{m} / \mathrm{s} ; n_{\mathrm{O}_{2}, \infty}$ - relative mass concentration of oxygen outside the suspension: for oxygen in the air $n_{\mathrm{O}_{2}, \infty}=0.23$.

\section{Calculation Results and Discussion}

Thus, the physico-mathematical model (1)-(11) describes the nonstationary high-temperature heat and mass transfer and the kinetics of chemical transformations of the polydisperse carbon particles-gas mixture. So, it is possible to determine the main characteristics of combustion of a carbon particles-gas suspension by solving these equations: the ignition delay, the burning time and temperature, and the critical parameters of ignition and extinction.

We present the temperature-time histories of particles of each fraction, the gas temperature history, and the particle temperature time derivatives during the combustion of a two-fraction $(i=2)$ carbon suspension at different gas temperatures. The initial mass concentration of the carbon fuel in the particles-gas suspension is $C_{m b}=0.0244 \mathrm{~kg} / \mathrm{m}^{3}$, the mass concentrations of fractions are the same: $C_{m b 1}=C_{m b 2}=0.0122 \mathrm{~kg} / \mathrm{m}^{3}$. This mass concentration corresponds to the stoichiometric composition of the carbon-air mixture $[1,2]$. Therefore, the amount of oxygen is sufficient for the complete fuel burnout. We determine the instants of the ignition $(I)$ and extinction $(E)$ of particles by extrema on the dependence $d T / d t(t)$ and calculate the ignition delay time and the burning time.

The analysis of the temperature histories shows that, at high gas temperatures, the ignition and burning of the fine fraction occur firstly (Fig. 1, $a, b$ ). Coarse particles ignite shortly before the extinction of fine particles. During the burning of fine particles, the oxygen concentration decreases substantially. So, the ignition and subsequent burning of coarse particles proceed at a low oxygen content.

At a relatively low gas temperature (Fig. 1, c, d), large particles ignite earlier (curves 2). According to (5), fine particles have a higher heat transfer coefficient. Therefore, the increase in the ignition delay of fine particles in comparison with the coarse particles is explained by the rise of heat losses from small particles into the surrounding gas, as its temperature decreases [see formula (4)].
As can be seen from Fig. 1, $d$, the ignition delay $t_{\text {ind }}$ (duration of the warm-up from the start to $I$ ) consists of two parts: the time of the particle inert heating up to the gas temperature (up to $I^{*}$ ) and the time of the heating by chemical reactions (from $I^{*}$ up to $I$ ). As the temperature of the surrounding gas decreases for small particles, the time of the chemical stage increases, during which the temperature of the gas in the gas suspension section reaches a higher value necessary for the ignition. Thus, in the hightemperature range, the ignition delay time of a twofraction particles-gas suspension is determined by the ignition delay of small particles and, at low temperatures, by the ignition delay of large-particle particles (Fig. 2, a).

At a certain critical value of the gas temperature $T_{\text {cr }}$ (Fig. 2, a), the suspension does not ignite. The critical ignition temperature of a two-fraction particles-gas suspension is significantly lower than the ignition temperature of an equal-sized single particle. Moreover, the critical temperatures of ignition differ substantially for single large and small particles $\left(T_{g . c r 1}=1370 \mathrm{~K}, T_{g . c r 2}=1280 \mathrm{~K}\right)$, and they practically coincide in the two-fraction particles-gas suspension (Fig. 2, a).

It should be noted that, near the critical gas temperature, a single particle ignition delay is much less than the ignition delay time of an equal-sized particle in the particles-gas suspension (Fig. 3).

It follows from Fig. 3, $c$ and $d$ that, for a single particle, the critical ignition conditions are pronounced clearly. If the gas temperature decreases by one degree, the particle does not ignite. It warms up to a temperature slightly above the gas temperature (curve 2). The critical extinction conditions of the burning particle are also clearly expressed. When the particle diameter reaches a critical value, its temperature and oxidation rate sharply decrease (curves 1, Fig. 3, c, d). The extinction of the particles-gas suspension occurs in a degenerate regime because of the approximate equality of the temperatures of a gas and particles (Fig. 3, $a$, $b)$. There is no sharp bend on the curve $d(t)$ that characterizes the abrupt change in the oxidation regime.

The burning temperature of fine particles at a low gas temperature is lower than that of coarse particles (Fig. 2, b) due to large heat losses to a gas and the lack of an oxidizer at the stage of combustion. The

ISSN 2071-0194. Ukr. J. Phys. 2018. Vol. 63, No. 4 

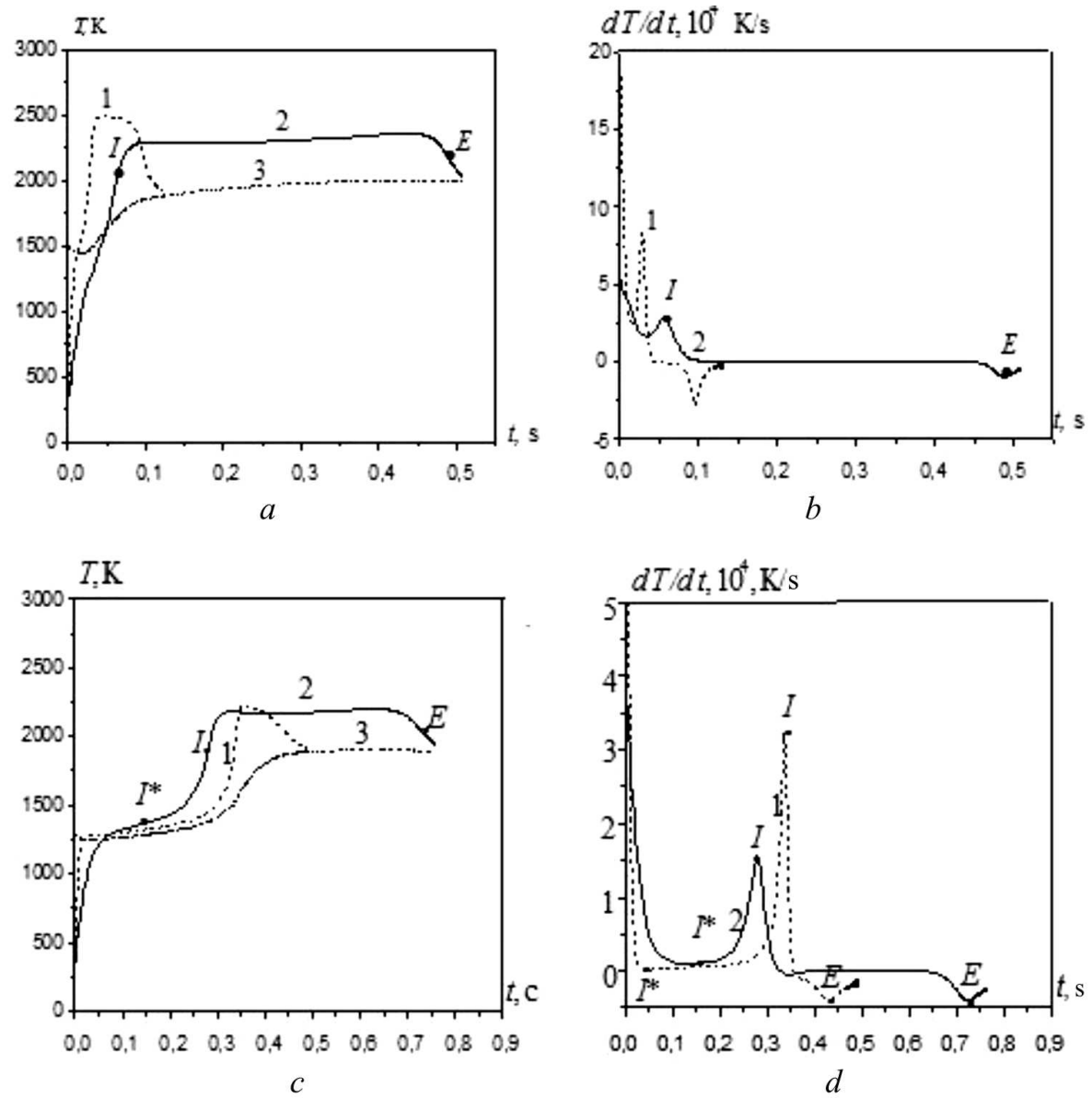

Fig. 1. Time histories of $T, T_{g}, d T / d t$ for a two-fraction particles-gas suspension at $(a, b)$ $T_{g \infty}=T_{w}=1500 \mathrm{~K} .(c, d) T_{g \infty}=T_{w}=1300 \mathrm{~K} .1-d_{b 1}=60 \mu \mathrm{m}, 2-d_{b 2}=120 \mu \mathrm{m}, 3-$ gas temperature $T_{g} . C_{m b}=0.0244 \mathrm{~kg} / \mathrm{m}^{3}$
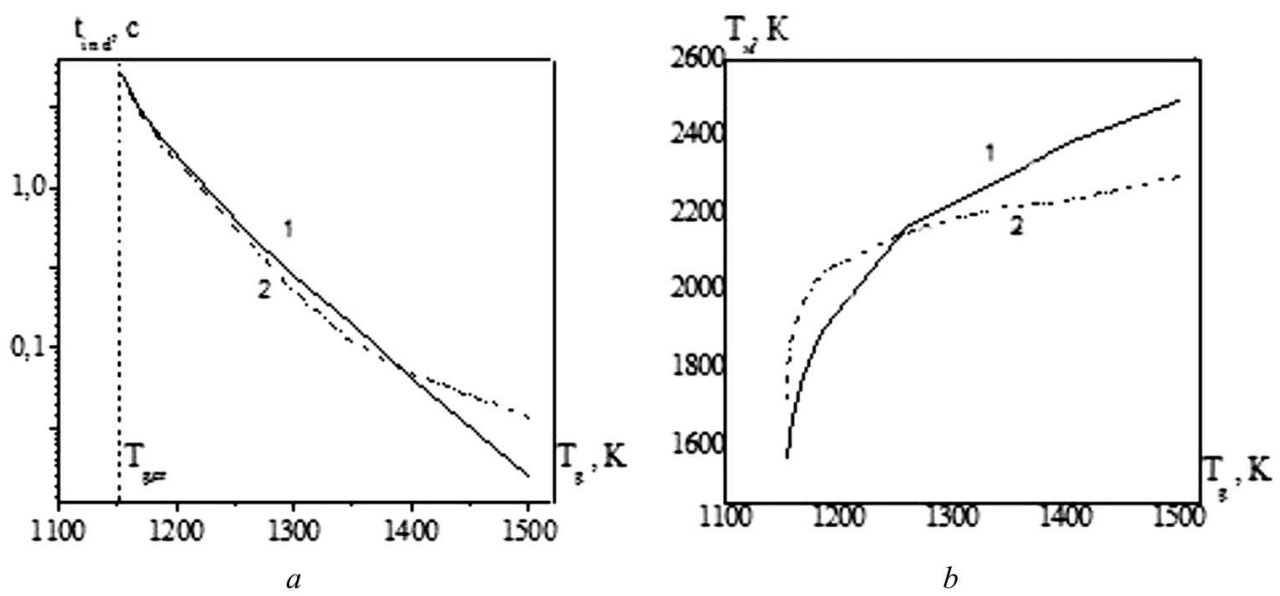

Fig. 2. Dependence of the ignition delay $(a)$ and the maximum burning temperature $(b)$ of particles of a two-fraction suspension on the gas temperature, $1-d_{b 1}=60 \mu \mathrm{m}, 2-d_{b 2}=120 \mu \mathrm{m}$ 

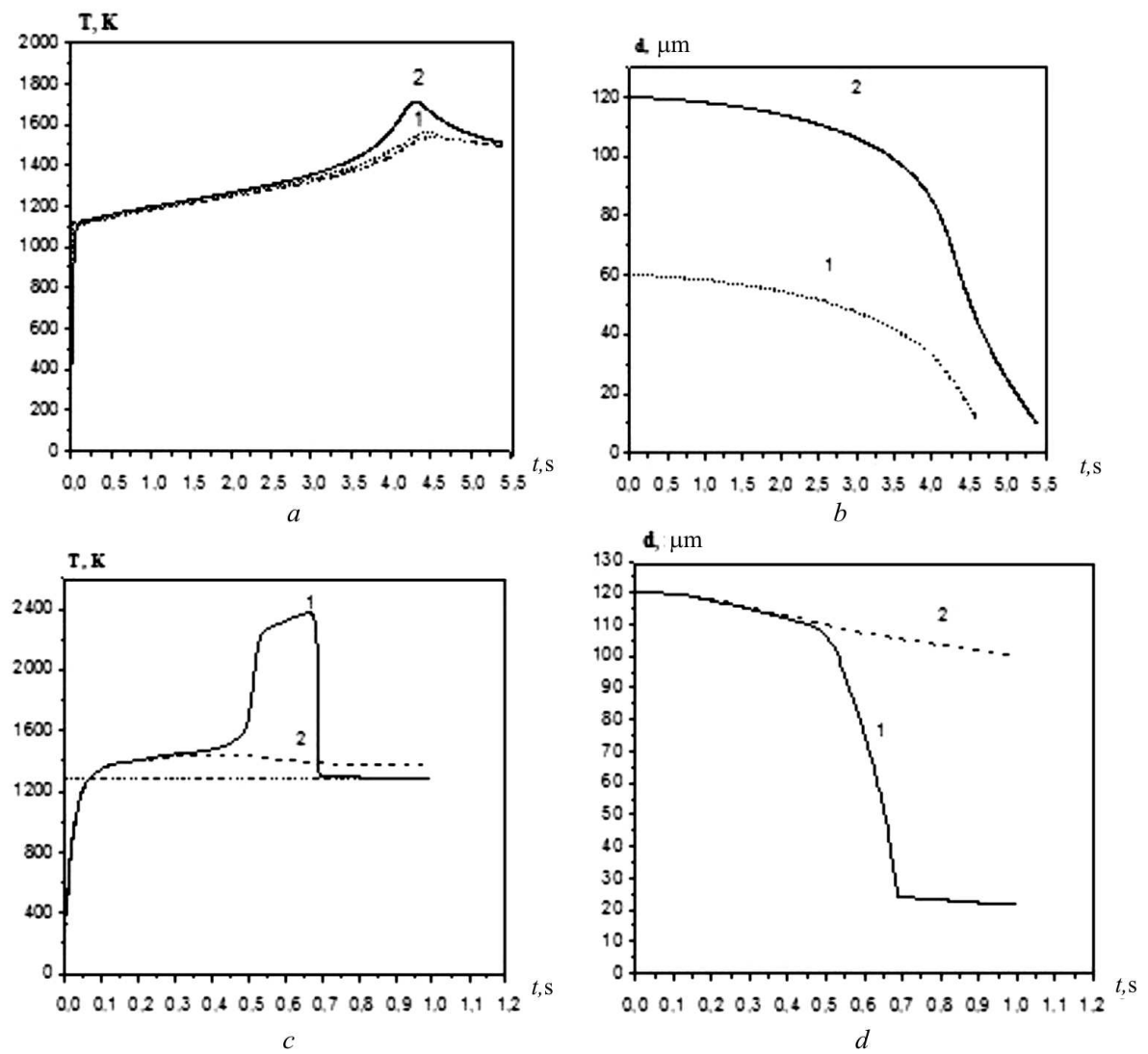

Fig. 3. The temperature and particle diameter histories near the critical ignition conditions: $(a, b)$ a two-fraction gas suspension, $1-d_{b 1}=60 \mu \mathrm{m}, 2-d_{b 2}=120 \mu \mathrm{m}, T_{g \infty}=1155 \mathrm{~K} ;(c$, d) single particle $d_{b}=120 \mu \mathrm{m}, 1-T_{g \infty}=1280 \mathrm{~K} ; 2-T_{g \infty}=1279 \mathrm{~K}$

oxygen concentration is significantly reduced at the ignition of fine particles due to its consumption by large-sized particles.

\section{Conclusions}

Thus, it is established that, at gas temperatures above $1400 \mathrm{~K}$, the ignition delay of a two-fraction carbon particles-gas suspension is determined by the ignition delay of fine particles and, at a gas temperature below this value, by the ignition delay of the coarse particles. This fact is a result of the increase in heat losses by the molecular convection to the surrounding gas from the small particles. The ignition temperature of the two-fraction particles-gas suspension is determined. The range of the ambient gas temperature and that of the reaction vessel walls is determined, for which the burning temperature of fine particles is less than that of coarse particles.
1. V.V. Pomerancev. Bases of the Practical Theory of Burning [in Russian], (Energia, 1973).

2. V.I. Babiy, Yu.F. Kuvaev. Combustion of Carbon Dust and Calculation of a Pulverized Coal Flare [in Russian], (Energoatomizdat, 1986).

3. S.G. Orlovskaya, V.V. Kalinchak, O.N. Zuy, O.V. Mandel, S.V. Kachan. High-temperature heat and mass transfer and critical phenomena in the gas mixtures of carbon particles. Ukr. J. Phys. 56, 1304 (2011).

4. S.G. Orlovskaya. Investigation of the regularities of combustion of gas suspensions of carbon particles. Phys. Chem. Solid State 16 (1), 210 (2015).

5. V.V. Kalinchak, O.N. Zuj, S.G. Orlovskaya. The effect of the temperature and diameter of porous carbon particles on the kinetics of chemical reactions and heat and mass transfer with air. High Temper. 43 (5), 781 (2005).

6. S.G. Orlovskaya, V.V. Kalinchak, O.N. Zuj. Effect of an internal reaction on the characteristics of high-temperature heat and mass transfer of gas suspensions of carbon particles. High Temper. 52 (5), 715 (2014).

ISSN 2071-0194. Ukr. J. Phys. 2018. Vol. 63, No. 4 
7. V.V. Kalinchak, S.G. Orlovskaya, A.I. Kalinchak, A.V. Dubinskiy. Heat and Mass Tranfer Between a Carbon Particle and Air in View of Stefan Flow and Heat Losses Due to Radiation. High Temper. 34 (1), 79 (1996).

Received 27.02.18

С.Г. Орловсъка, В.В. Калінчак, О.М. Зуй, М.В. Лисянсъка ДОСЛІДЖЕННЯ ЗАЙМАННЯ ТА ГОРІННЯ ДВОКОМПОНЕНТНОГО ГАЗОЗАВИСУ ВУГЛЕЦЕВИХ ЧАСТИНОК

Р е $з$ ю м е

В роботі вивчаються характеристики займання і горіння двофракційного газозавису вуглецевих частинок в повітрі при різних температурах. Важливими характеристиками спалювання палив є: період індукції (час, за який частинки спалахують), температура і час горіння, критичні температури, діаметри і масові концентрації частинок в газозависі, що визначають їх займання та потухання. Дослідження полягали в розробці фізико-математичної моделі високотемпературного тепломасообміну та кінетики хімічних перетворень сукупності вуглецевих частинок у газовому середовищі, що містить окислювач, і проведенні чисельного експерименту. Для розрахунків вибирався двофракційний газозавис з діаметрами частинок дрібної фракції 60 мкм, великої фракції 120 мкм і рівними масовими концентраціями фракцій. Діапазон досліджуваних температур газу 1100-1500 K. 